\title{
Guanidino Compounds as Cause of Cardiovascular Damage in Chronic Kidney Disease: An in vitro Evaluation
}

\author{
Eva Schepers $^{a} \quad$ Griet Glorieux $^{a} \quad$ Laetitia Dou $^{b} \quad$ Claire Cerini $^{b} \quad$ Nathalie Gayrard $^{c}$ \\ Loïc Louvet $^{d} \quad$ Charlotte Maugard $^{d}$ Pierre Preus $^{\mathrm{e}}$ Maria Rodriguez-Ortiz ${ }^{f}$ \\ Angel Argiles $^{c}$ Philippe Brunet ${ }^{b}$ Gerald Cohen ${ }^{g}$ Joachim Jankowski ${ }^{\mathrm{e}}$ \\ Vera Jankowski ${ }^{\text {Ziad Massy }}{ }^{d}$ Mariano Rodriguez ${ }^{f}$ Raymond Vanholder ${ }^{a}$ \\ for the European Uremic Toxin Work Group (EUTox)

\begin{abstract}
${ }^{a}$ Nephrology Division, Department of Internal Medicine, University Hospital Gent, Gent, Belgium; bINSERM UMR 608, Aix-Marseille Université Marseille, Marseille, 'SAS RD - Néphrologie and Institute of Functional Genomics, Montpellier, and IINSERM ERI-12, University de Picardie Jules Verne, Amiens University Hospital, Amiens, France; e Medizinische Klinik IV, Campus Benjamin Franklin, Charité - Universitätsmedizin Berlin, Berlin, Germany;

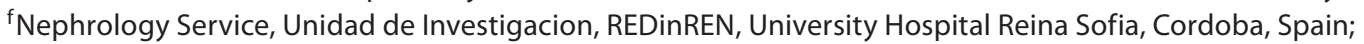
${ }^{9}$ Division of Nephrology and Dialysis, and Department of Medicine III, Medical University of Vienna, Vienna, Austria
\end{abstract}

\section{Key Words}

Atherosclerosis $\cdot$ Chronic kidney disease $\cdot$ Guanidino compounds · SDMA · Uremic toxins - Vascular damage

\begin{abstract}
Chronic kidney disease is considered a major cause of cardiovascular risk and non-traditional risk factors remain largely unknown. The in vitro toxicity of 10 guanidino compounds (GCs) was evaluated via a standardized approach on different cell systems of relevance in cardiovascular disease. The parameters evaluated were production of reactive oxygen species, expression of surface molecules, cell proliferation, cytotoxicity and calcification. Several GCs had a stimulatory effect on monocytes and granulocytes (SDMA, creatine and guanidinobutyric acid (GBA)). Some GCs (guandine (G), guanidinosuccinic acid (GSA) and SDMA) inhibited endothelial cell proliferation or reduced calcification in osteoblast-like human VSMC (ADMA, GSA and SDMA). Stimulation of osteo-
\end{abstract}

clastogenesis could be demonstrated for ADMA, G, guanidinoacetic acid and GBA in a RAW264.7 cell line. No compounds were cytotoxic to AoSMC or endothelial cells, nor influenced their viability. GCs, especially SDMA, likely contribute to cardiovascular complications in uremia, mainly those related to microinflammation and leukocyte activation.

Copyright $\odot 2010$ S. Karger AG, Basel

\section{Introduction}

Chronic kidney disease (CKD) is from the early stages on complicated by cardiovascular disease (CVD) in a large majority of patients $[1,2]$. More than half of hemodialysis patients die from cardiovascular events and survival of dialysis patients at start is worse than that of most malignancies at diagnosis [3].

\section{KARGER}

Fax +41613061234 E-Mail karger@karger.ch www.karger.com
(C) 2010 S. Karger AG, Basel

0253-5068/10/0304-0277\$26.00/0

Accessible online at:

www.karger.com/bpu
Raymond Vanholder, MD, $\mathrm{PhD}$

Department of Internal Medicine, Nephrology Division, University Hospital Gent De Pintelaan 185, BE-9000 Gent (Belgium)

Tel. +329 33245 25, Fax +3293324599

E-Mail Raymond.Vanholder@UGent.be 
According to the latest analysis, more than $10 \%$ of the US population suffers from advanced CKD [4]. Knowledge of the factors affecting cardiovascular status in this population is therefore of key importance. Although traditional factors play a role, a broad range of pathophysiological mechanisms induced by less traditional risk factors seems to be involved as well [5]. One of these is microinflammation, which by itself is a cardiovascular risk factor. Renal failure from its early stages on induces a status of microinflammation, which as such is the consequence of the retention of a host of as yet largely unknown compounds [6]. These compounds, excreted into the urine by the healthy kidneys, accumulate in the body and are called uremic retention solutes [7]. Next to inflammation, other elements also play a key role in cardiovascular damage, such as smooth muscle cell proliferation, endothelial damage and the subtle interplay between bone and vessels via mineral metabolism $[8,9]$. Therefore, all these factors should be considered in the quest for compounds at play in CVD of CKD.

Among the substances accumulated in uremia, the guanidino compounds (GCs) are a large group of lowmolecular-weight, water-soluble uremic toxins. They are structural metabolites of L-arginine and increased levels of these compounds have been determined in serum, urine, cerebrospinal fluid and brains of uremic patients [10, 11]. De Deyn et al. [12] extensively described the involvement of GCs in neurotoxicity and sporadic reports have demonstrated a pro-inflammatory impact of certain GCs. Glorieux et al. [13] demonstrated that GCs activate baseline immune status, and Perna et al. [14] showed their involvement in decreasing protein binding of homocysteine. They have also been related to the propensity for infection of uremic patients [13]. Asymmetric dimethylarginine (ADMA), a known inhibitor of nitric oxide synthase, as a marker of endothelial dysfunction has been related to several parameters of vascular outcome [15-19]. Its structural counterpart symmetric dimethylarginine (SDMA), considered inert, was recently shown to increase activation of reactive oxygen species (ROS) production in endothelial cells via inhibition of nitric oxide synthesis and in monocytes via store-operated calcium channel-mediated calcium entry $[20,21]$.

In the present study, the potential of a broad group of GCs to damage vessels is analyzed in vitro via a holistic approach, involving several test systems of vascular pathophysiology in parallel.
Table 1. List of the GCs tested and the concentration at which they were tested

\begin{tabular}{lrc}
\hline Guanidino compounds & Concentration, $\mu \mathrm{M}$ & Ref. \\
\hline Asymmetric dimethylarginine & 36.1 & 24 \\
Creatine & 556.0 & 23 \\
Creatinine & 2123.9 & 28 \\
Guanidine & 13.6 & 26 \\
Guanidino acetic acid & 5.9 & 23 \\
$\gamma$-Guanidino butyric acid & 12.1 & 26 \\
B-Guanidino propionic acid & 0.5 & 27 \\
Guanidino succinic acid & 268.6 & 26 \\
Methylguanidine & 24.9 & 26 \\
Symmetric dimethylarginine & 6.1 & 25 \\
\hline
\end{tabular}

\section{Materials and Methods}

ADMA.2HCl and SDMA.2HCl were obtained from Calbiochem (San Diego, Calif., USA), creatine monohydrate (CT) and creatinine (CTN) were purchased from Merck (Hohenbrunn, Germany). All the other GCs listed in table 1 were purchased from Sigma-Aldrich Co. (St. Louis, Mo., USA).

\section{General Experimental Set-Up}

Following a standardized approach for in vitro research in uremia, described by Cohen et al. [22], 10 $\times$ stock solutions of the $\mathrm{GCs}$, to be stored at $-20^{\circ} \mathrm{C}$, were prepared in saline $(0.9 \% \mathrm{NaCl})$ corresponding to the high range of reported uremic plasma concentrations (table 1) [23-28].

Studies on Leukocytes

Whole Blood

Heparinized whole blood (sodium heparin, Vacutainer ${ }^{\mathrm{TM}}$, Becton Dickinson, San Jose, Calif., USA) from healthy volunteers was collected after informed consent. Exclusion criteria were smoking, infection, pregnancy or medication intake affecting the immune status. The study protocol was approved by the local ethics committee.

Oxidative Burst Activity. After a 10-min incubation period of the whole blood at $37^{\circ} \mathrm{C}$ with saline (control) or the GCs, their effect on the leukocyte oxidative burst activity was evaluated using the Bursttest (Phagoburst ${ }^{\circledR}$ ) (Orpegen Pharma, Heidelberg, Germany), as described previously [29]. Oxidative burst activity was measured at baseline, after stimulation with N-formyl-methionine-leucine-phenylalanine (fMLP, $0.83 \mu \mathrm{M})$, Escherichia coli $\left(1.66 \times 10^{8} \mathrm{cells} / \mathrm{ml}\right)$ and phorbol-12-myristate-13-acetate (PMA, $1.35 \mu \mathrm{M})$ by flow cytometry. Monocytes, granulocytes and lymphocytes were gated separately in the light scatter dot blot according to size (forward scatter) and granularity (side scatter).

Expression of Cell Surface Molecules. The surface expression of CD11a, CD11b, CD11c, CD14, CD18 and CD62L on leukocytes was assessed after incubation of whole blood with the GCs (60 min, $37^{\circ} \mathrm{C}$ ). After addition of fluorescence-labeled monoclonal antibodies (10 min, room temperature), a combination of fluorescein isothiocyanate (FITC)-anti-CD11a, phycoerythrin-cyanine 
5 (PC5)-anti-CD11b, phycoerythrin-Texas Red conjugate (ECD)anti-CD14 and phycoerythrin (PE)-anti-CD18 antibodies and a combination of PE-anti-CD11c, ECD-anti-CD14, FITC-antiCD62L were analyzed in parallel. Erythrocytes were lysed using automatic sample processing with the ImmunoPrep Reagent System (Beckman Coulter Inc., Miami, Fla., USA) and the Multi-QPrep (Coulter International Corp., Hialeah, Fla., USA). Samples were immediately analyzed on the Epics XL-MCL flow cytometer (Coulter International Corp.) in a four-color set-up. Granulocytes and monocytes were gated using forward (FSC) versus side scatter (SSC) characteristics and SSC versus CD14 expression, respectively. Per sample 10,000 granulocytes and approximately 1,000 monocytes were analyzed. Basal expression of the control sample (saline) was set as $100 \%$.

\section{Isolated Lymphocytes}

Lymphocytes were isolated from whole blood as described previously [30]. The lymphocyte pellets were resuspended in distilled water and were lysed after several freeze-thawing cycles to obtain cell membranes containing NADPH oxidase, the major ROS-generating enzyme.

NADPH Oxidase Activity. GCs were added to the lysed lymphocytes in a 96-well plate with $5 \mathrm{mM} \mathrm{NADPH}$ in the presence or absence of $4.8 \mathrm{~mm}$ diphenyl iodonium, a specific inhibitor of NADPH oxidase. By means of a microtiter plate reader (Multiskan Ascent, Thermo Electron Corp., Waltham, Mass., USA), the change in absorbance of the NADPH substrate was measured photometrically at $340 \mathrm{~nm}$ after an incubation period of $90 \mathrm{~min}$. The effect of normal plasma concentrations, as described by Vanholder et al. [27], was set as $100 \%$.

\section{Studies on Endothelial Cells}

Human Umbilical Vein Endothelial Cells (HUVEC)

HUVEC were obtained from umbilical cord veins by collagenase digestion [31], seeded on gelatin-coated (Invitrogen) culture plates and grown in EGM-2 medium (Clonetics BioWhittaker, Verviers, Belgium) under standard conditions (humidified atmosphere, $5 \% \mathrm{CO}_{2}, 37^{\circ} \mathrm{C}$ ). Cells were then detached with a $0.05 \%$ trypsin- $0.02 \%$ EDTA solution (Invitrogen) and subcultured to a second passage on collagen-coated 96-well culture plates.

Proliferation Assay. The effect of GCs on endothelial cell proliferation was assessed by bromo-2'-deoxyuridine (BrdU) incorporation into cellular DNA with the Cell Proliferation ELISA BrdU kit obtained from Roche (Meylan, France) [32].

Cytotoxicity Assay. Cytolysis of the HUVECs, incubated overnight with saline (control) or GCs $\left(37^{\circ} \mathrm{C}\right)$, was measured by evaluating lactate dehydrogenase ( $\mathrm{LDH})$-release using the $\mathrm{LDH}$-cytotoxicity detection kit (Roche, Basel, Switzerland) according to the manufacturer's instructions.

Aortic Endothelial Cells

Human aortic endothelial cells (HAEC) were purchased from Lonza (Walkersville, Md., USA) and cultured in EGM-2 Bullet kit medium (Lonza) $\left(37^{\circ} \mathrm{C}, 5 \% \mathrm{CO}_{2}\right)$. Passages $4-5$ of the HAEC were seeded on 96-well plates and grown to $90 \%$ confluence.

Cytotoxicity Assay. HAEC were incubated with saline (control) or GCs $\left(24 \mathrm{~h}, 37^{\circ} \mathrm{C}\right)$. Cytolysis was measured by evaluating $\mathrm{LDH}$ release using the $\mathrm{LDH}$ cytotoxicity detection kit.

Proliferation/Cytotoxicity Assay, ATP Levels. In parallel with $\mathrm{LDH}$ release, cytotoxicity of the GCs on the HAEC was also eval- uated by determination of their ATP levels using the ViaLight ${ }^{\mathrm{TM}}$ bioluminescence assay (Lonza) as described by the manufacturer.

Studies on Smooth Muscle Cells

Aortic Smooth Muscle Cells (AoSMC)

Human AoSMC were purchased from Lonza and cultured in SmGM-2 Bullet kit medium (Lonza) under the same conditions as HAEC.

Cytotoxicity Assays. The HAoSMC were incubated with the GCs $\left(24 \mathrm{~h}, 37^{\circ} \mathrm{C}\right)$ and both the LDH assay and the ATP assay were performed as described above.

Human Vascular Smooth Muscle Cell (HVSMC) Culture

HVSMCs were obtained from a primary culture of aorta explants obtained during cardiac surgery. Medial tissue was separated and pieces of tissue $\left(1-2 \mathrm{~mm}^{2}\right)$ were cultured in $60-\mathrm{mm}$ dishes for 2 weeks in pyruvate-enriched DMEM containing $15 \%$ fetal calf serum (FCS). Cells were then collected and routinely cultured in this medium. HVSMC stained positive for smooth muscle $\alpha$-actin. Cells were assessed between passages 2 and 8 .

Proliferation and Viability Assessment. HVSMCs were trypsinized and seeded in 96-well plates at a density of $3.2 \times 10^{3}$ cells/ well. After overnight starvation (0.5\% FCS), HVSMCs were cultured for 7 days, under starvation conditions as a negative control $(\mathrm{Ct}-)$ and in DMEM containing 5\% FCS as a positive control $(\mathrm{Ct}+)$. GCs were added to DMEM with 5\% FCS and the addition of 100 $\mathrm{ng} / \mathrm{ml}$ epidermal growth factor was used as a proliferation control. Cell proliferation and viability were measured at the end of the experiment by addition of the water-soluble tetrazolium salt WST-1 (Roche). The WST-1 metabolized by the active cells was quantified by measuring the optical density values (ODs) at 450 and $630 \mathrm{~nm}$ as a reference using a microplate reader. Results were expressed as percentage versus $\mathrm{Ct}+$.

Calcification Assessment. To study calcification, HVSMCs were trypsinized and seeded overnight in 48 -well plates at a density of $7.5 \times 10^{3}$ cells/well. Media were replaced by DMEM with $5 \%$ FCS without inorganic phosphate $(\mathrm{Pi})$ as a control $(\mathrm{Ct})$ or with $\mathrm{Pi}$ (final concentration $3 \mathrm{~mm} \mathrm{Pi}$ ) to induce osteoblast-like cells [33]. GCs were added with or without Pi. Media were replaced twice a week and cells were cultured for 9 days. Mineralization of the extracellular matrix was determined using alizarin red S (Sigma). Cells were washed with PBS, fixed with $70 \%$ ethanol $(30$ $\mathrm{min})$, washed again and stained with $1 \%(\mathrm{w} / \mathrm{v})$ alizarin red in water ( $\mathrm{pH} 4.2,5 \mathrm{~min}$, room temperature), followed by water rinsing. For quantification of the mineralization, the alizarin red was extracted with $10 \mathrm{~mm}$ cetylpyridinium chloride (Sigma). The extracted stain was diluted 1:1 with water and absorbance at $570 \mathrm{~nm}$ and a reference at $750 \mathrm{~nm}$ was measured using a microplate reader. Results were expressed as percentage versus Ct.

Studies on Osteoclast-Like Cells

RAW264.7 mouse monocyte/macrophage cells were purchased from the American Type Culture Collection (TIB-71, ATCC, France) and routinely cultured in DMEM containing $10 \%$ FCS.

Proliferation and Viability Assessment. To study RAW264.7 proliferation, cells were gently scraped and seeded in 96-well plates at a density of $5 \times 10^{3}$ cells/well. After overnight starvation ( $0.5 \%$ FCS), media were replaced by DMEM with $0.5 \%$ FCS as a negative control (Ct-) and with $10 \%$ FCS as a positive control 

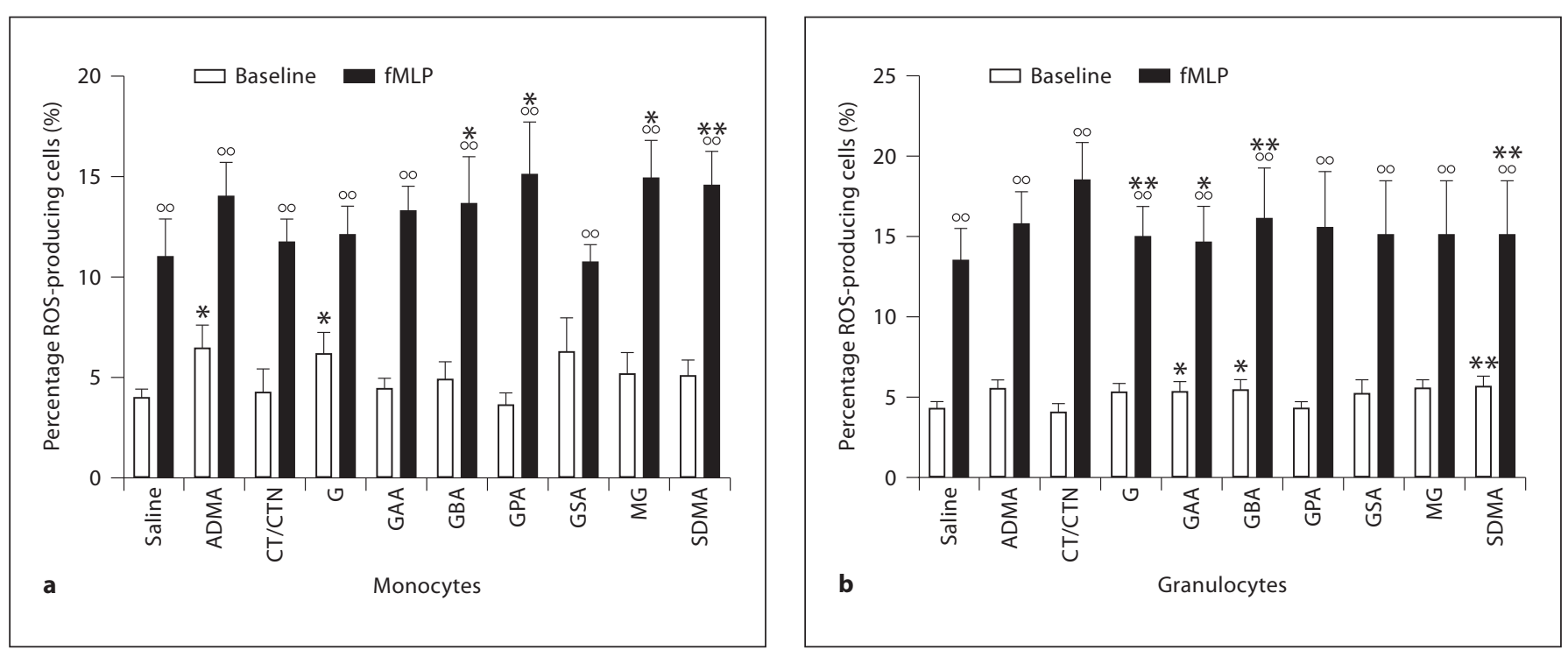

Fig. 1. Oxidative burst activity of whole blood monocytes (a) and granulocytes (b) following incubation with GCs. Data are shown as the percentage of ROS-producing cells and are given for unstimulated leukocytes (white bars, baseline) and fMLP-stimulated leukocytes (black bars). The bars represent the mean \pm SEM. ${ }^{*} \mathrm{p}<0.05$, ${ }^{* *} \mathrm{p}<0.01$ vs. saline (control); ${ }^{\circ} \mathrm{p}<0.01$ vs. baseline; $\mathrm{n}=8$.

$(\mathrm{Ct}+)$. GCs were added to DMEM with $10 \%$ FCS and cell proliferation and viability were measured with the use of WST-1 as described above.

Osteoclastic Differentiation by Measurement of Tartrate-Resistant Acid Phosphatase (TRAP) Activity. To study RAW264.7 cell differentiation into osteoclast-like cells (OCLs), they were gently scraped and seeded in 96 -well plates at a density of $10^{3}$ cells/ well. After $2 \mathrm{~h}$, media were replaced by $\alpha$-MEM supplemented with $10 \%$ FCS without (Ct-) or with $(\mathrm{Ct}+) 30 \mathrm{ng} / \mathrm{ml}$ recombinant murine Receptor Activator of NFкB Ligand (RANKL) (Ct+). GCs were added both with and without RANKL supplementation. Media were replaced once and cells were cultured for 5 days. TRAP activity was assessed as previously described $[32,34]$, and results, normalized on a protein basis, are expressed as percentage TRAP activity versus $\mathrm{Ct}+$.

\section{Endotoxin Contamination}

Experimental solutions were checked for endotoxin contamination by means of the Limulus Amebocyte Lysate (LAL) QCL1000-test (Lonza).

\section{Statistical Analysis}

Data are expressed as mean \pm SEM. Statistical analysis was performed with the Prism software (GraphPad Software Inc., San Diego, Calif., USA). Determination of significant differences was performed using a non-parametric paired Wilcoxon test or MannWhitney test or a parametric unpaired or paired t test as appropriate. $\mathrm{p}$ values $<0.05$ were considered significant.

\section{Results}

\section{Leukocyte Function}

ROS Production and CD Expression in Whole Blood Monocytes

At baseline, less than $5 \%$ of the monocytes produced free radicals ( $3.9 \pm 0.5, \mathrm{n}=8$, fig. 1a); in the presence of ADMA and guanidine (G), an increased basal oxidative burst activity was observed. In fMLP-stimulated monocytes, the percentage of ROS-producing monocytes was significantly higher versus baseline in all tested conditions. Guanidino butyric acid (GBA), guanidino propionic acid (GPA), methylguanidine $(\mathrm{MG})(\mathrm{p}<0.05)$ and SDMA ( $p<0.01)$ enhanced the fMLP-stimulated burst activity compared to saline (fig. 1a). After stimulation with PMA, only guandino succinic acid (GSA) induced a significant increase in mean fluorescence intensity versus saline $(150.5 \pm 8.3$ vs. $123.1 \pm 15.0, \mathrm{p}<0.05, \mathrm{n}=8)$ (data not shown). These results are compatible with a pro-inflammatory effect of specific GCs on monocytes.

The surface expression of CD14, a marker for monocyte differentiation, the $\alpha$-components of integrins (CD11a, CD11b and CD11c) and their common $\beta$-component CD18 were measured on monocytes (table 2). CD14 showed an increased expression in the presence of all GCs, except for G. CT induced an increased surface ex- 
Table 2. Effects of the GCs on the expression of CD markers in whole blood monocytes and granulocytes

\begin{tabular}{|c|c|c|c|c|c|c|c|c|c|c|}
\hline & \multicolumn{5}{|c|}{ Monocytes } & \multicolumn{5}{|c|}{ Granulocytes } \\
\hline & CD11a & CD11b & CD11c & CD14 & CD18 & CD11a & CD11b & CD11c & CD18 & CD62L \\
\hline ADMA & - & - & - & $4 \pm 2^{*}$ & - & - & - & $11 \pm 4^{*}$ & - & $-8 \pm 3^{*}$ \\
\hline $\mathrm{CT}$ & $9 \pm 2^{* *}$ & $30 \pm 10^{* *}$ & $22 \pm 5^{* *}$ & $18 \pm 3^{* *}$ & $23 \pm 5^{* *}$ & - & - & $13 \pm 7^{* *}$ & $17 \pm 3^{* *}$ & - \\
\hline CTN & - & - & - & $14 \pm 4^{* *}$ & - & - & - & - & $11 \pm 4^{* *}$ & - \\
\hline G & - & - & - & - & - & - & - & - & $6 \pm 2^{*}$ & - \\
\hline GAA & - & - & - & $18 \pm 5^{* *}$ & - & - & - & - & - & - \\
\hline GBA & - & - & $14 \pm 4^{*}$ & $16 \pm 5^{* *}$ & - & - & - & $21 \pm 10^{*}$ & $18 \pm 8^{*}$ & - \\
\hline GPA & - & - & - & $17 \pm 4^{* *}$ & $21 \pm 10^{*}$ & - & - & - & $17 \pm 6^{* *}$ & - \\
\hline GSA & $6 \pm 1^{* *}$ & - & - & $22 \pm 3^{* *}$ & $13 \pm 5^{*}$ & - & - & - & $9 \pm 5^{* *}$ & $10 \pm 5^{*}$ \\
\hline MG & - & - & - & $17 \pm 4^{* *}$ & - & - & - & - & - & $-8 \pm 3^{* *}$ \\
\hline SDMA & $6 \pm 2^{*}$ & $15 \pm 6^{*}$ & - & $7 \pm 4^{*}$ & - & - & - & - & $5 \pm 2^{*}$ & $-13 \pm 6^{*}$ \\
\hline
\end{tabular}

Data represent the percentage change vs. saline \pm SEM. ${ }^{*} \mathrm{p}<0.05,{ }^{* *} \mathrm{p}<0.01$ vs. saline, $\mathrm{n}=8$.

pression of all measured CDs, GSA and SDMA of CD11a, SDMA of CD11b and GPA and GSA of CD18. Incubation with GBA significantly increased CD11c surface expression. Thus, the GCs also contribute to monocyte CD expression resulting in enhanced differentiation and adhesion capacity to the endothelium.

ROS Production and CD Expression in Whole Blood Granulocytes

As shown in figure $1 \mathrm{~b}, 4.2 \pm 0.4$ granulocytes were rhodamine-positive at baseline; after incubation with guanidino acetic acid (GAA), GBA and SDMA an increased percentage of ROS-producing granulocytes is observed. Also the granulocytes showed an increased ROS production in response to fMLP versus baseline. Addition of G, GAA, GBA and SDMA to the blood induced a further significant rise after fMLP stimulation as compared to saline (fig. 1b).

In the presence of GPA and MG, an inhibition of the mean fluorescence intensity of granulocytes was seen on the E. coli-stimulated burst activity $(491.3 \pm 104.9$ and $497.2 \pm 81.0$, respectively, vs. $549.1 \pm 106.2)$ and none of the GCs had a significant effect on the PMA-stimulated ROS production (data not shown).

The surface molecules evaluated on granulocytes were the integrin components and CD62L (L-selectin). CD11c expression was significantly increased in the presence of ADMA, CT and GBA and CD18 expression in the presence of CT, CTN, G, GBA, GPA, GSA and SDMA (table 2). CD62L surface expression was enhanced by GSA and inhibited by ADMA, MG and SDMA.

Contribution of Guanidines to Uremic Toxicity
For the granulocytes thus both pro- and anti-inflammatory effects of the GCs could be observed.

ROS Production in Whole Blood Lymphocytes

None of the GCs had an effect on the lymphocyte oxidative burst activity (data not shown, $\mathrm{n}=8$ ).

\section{NADPH Oxidase Activity}

The activity of NADPH oxidase isolated from lymphocytes was enhanced in the presence of ADMA and GPA, while CT inhibited the enzyme (fig. 2). CTN, G and SDMA showed a trend to activate NADPH oxidase.

\section{Endothelial Cell Function}

Cell Proliferation in HUVEC

The endothelial proliferation of the cells incubated with saline (control) corresponded with an absorbance for BrdU incorporation of $1.201 \pm 0.025$. No effect on cell proliferation was noted with culture medium alone (data not shown, $n=7$ ). Among the different GCs tested, $G$, GSA, and SDMA inhibited endothelial proliferation (fig. 3 ) respectively by $8.3,9.5$ and $6.4 \%$ ( $\mathrm{p}<0.05$ vs. control). This inhibition of endothelial cell proliferation in the presence of specific GCs has the potential to contribute to the endothelial dysfunction in uremic patients.

\section{Cytolysis in HUVEC}

The different GCs tested did not induce significant cytolysis in HUVEC ( $\mathrm{n}=8)$, as measured by LDH release. Serum-starved HUVEC, used as a positive control, displayed significant increase in LDH release (data not shown).

Blood Purif 2010;30:277-287 


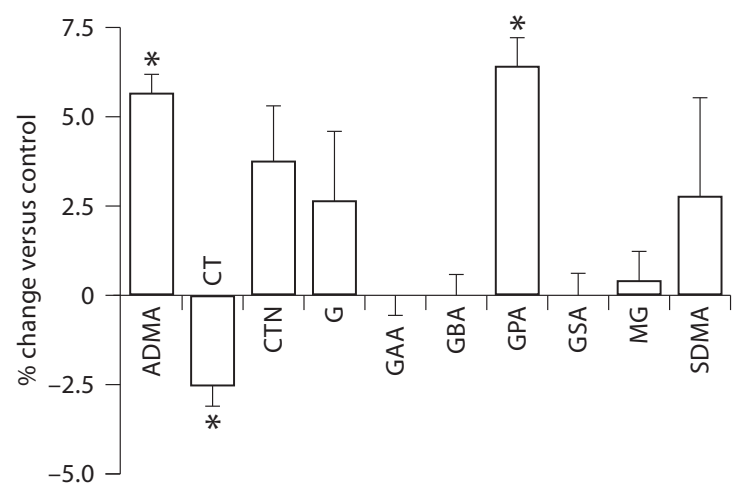

Fig. 2. Effect of individual GCs on the activity of NADPH oxidase. Data are shown as the percentage change of the effect at normal concentrations (control). The bars represent the mean \pm SEM. ${ }^{*} \mathrm{p}<0.05$ vs. control; $\mathrm{n}=6$.

Cytolysis and ATP Content in HAEC

Both on cytolysis and ATP content no significant differences were observed between the cells incubated with the different GCs and their respective controls (data not shown, $\mathrm{n}=6$ ). These results show that GCs are neither cytotoxic nor induce proliferation in HAEC.

\section{Smooth Muscle Cell Function}

Cytolysis and ATP Content in AoSMC

As observed for the HAEC, no significant effects of the GCs on AoSMC were observed on cytolysis and ATP content using the same experimental conditions (data not shown, $\mathrm{n}=6$ ). GCs are thus not cytotoxic or do not induce proliferation in AoSMC.

\section{Proliferation of HVSMCs}

None of the GCs showed an effect on the proliferation of HVSMCs for 7 days by using WST-1 reagent compared to $\mathrm{Ct}+$, whereas epidermal growth factor, the proliferation control, did (data not shown, $\mathrm{n}=24$ ).

\section{Pi-Induced Matrix Calcification in HVSMCs}

The GCs alone did not induce mineralization by HVSMCs (data not shown, $\mathrm{n}=4$ ). However, in combination with $\mathrm{Pi}(3 \mathrm{mM})$ as inducer of differentiation into osteoblast-like cells, calcification of HVSMCs was significantly decreased in the presence of ADMA, GSA and SDMA (fig. 4). These compounds may therefore prevent calcification in this osteoblast-like model.

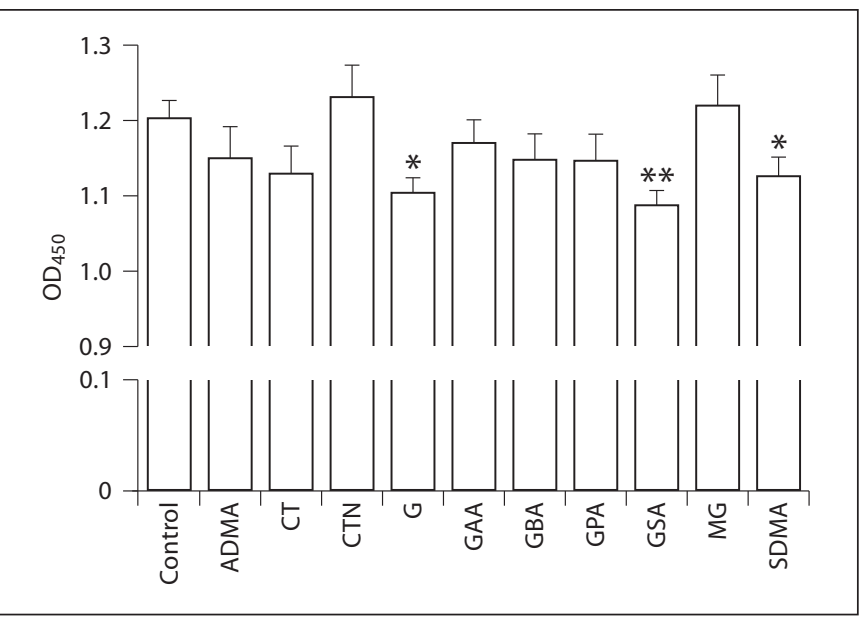

Fig. 3. Effect of the GCs on endothelial proliferation. Results are expressed as mean \pm SEM. ${ }^{*} \mathrm{p}<0.05$ vs. control; ${ }^{* *} \mathrm{p}<0.01$ vs. control; $\mathrm{n}=7$.

Osteoclast-Like Model

RAW264.7 Precursor Cells Proliferation

None of the GCs modulated the RAW264.7 precursor cell proliferation (data not shown, $\mathrm{n}=12$ ).

\section{RANKL-Induced Differentiation of RAW264.7 \\ Cells into OCLs}

As shown in figure 5, the RANKL-induced differentiation of RAW264.7 cells into OCLs was significantly increased in the presence of ADMA, G, GAA and GBA as measured by enhanced TRAP activity. Increase of TRAP in this cellular model directly correlates with an increased osteoclastic differentiation.

\section{Discussion}

Uremia is a complex syndrome in which dysfunction of multiple organs arises during progression of the disease and is attributed to the accumulation of uremic retention solutes. Up to now, in vitro research on these solutes in the different cell types and tissues involved is fragmentary, often using concentrations irrelevant for uremia and/or performed at non-comparable conditions.

The most important findings of this study are that after incubation of whole blood leukocytes with the GCs, at least two pro-inflammatory effects for each toxin could be observed and the presence of SDMA showed the highest number of effects on leukocytes. G, GSA and SDMA 


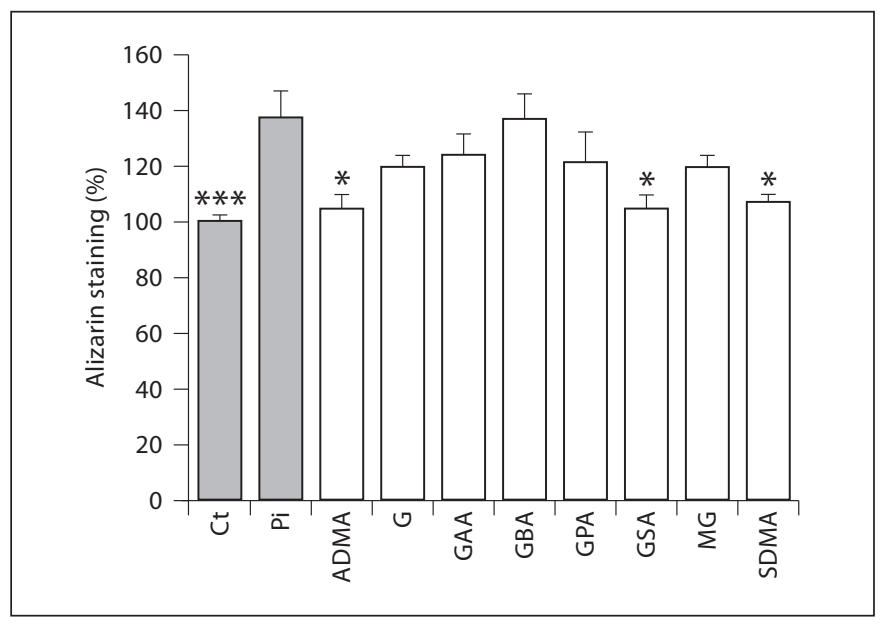

Fig. 4. Effect of GCs on Pi-induced calcification in HVSMC. Results have been expressed as mean of $\%$ vs. Ct \pm SEM. ${ }^{*} \mathrm{p}<0.05$, *** $\mathrm{p}<0.001$ vs. $\mathrm{Pi} ; \mathrm{n}=4$.

inhibited endothelial cell proliferation and a decrease in calcification of the osteoblast-like cells could be observed by ADMA, GSA and SDMA. Additionally, osteoclastogenesis was stimulated by ADMA, G, GAA and GBA.

The present study applies a multifaceted approach using standardized conditions needed to understand the pathophysiological impact of the retention solutes and was performed by parallel assessment methods in several laboratories which are members of the European Uremic Toxin work group (EUTox) [35]. The intention was to evaluate a panel of GCs, a group of water-soluble uremic retention solutes, in specific cell systems involved in CVD, the major cause of death in CKD. The GCs tested were ADMA, CT, CTN, G, GAA, GBA, GPA, GSA, MG and SDMA. In each in vitro set-up the compounds were added to cell systems (leukocytes, endothelial cells, smooth muscle cells and OCLs) at a consistent concentration corresponding to what is observed in uremic conditions [22, 27].

To the best of our knowledge, no previous efforts have been made to study the impact of uremic toxins in such a parallel and systematic manner. This holistic approach follows previous recommendations by the EUTox group [22]. It is in our opinion the only possibility to understand the impact of uremic toxicity on organs and organ groups with clinical relevance as well as to classify uremic toxins according to their biological importance.

The toxic effects of the GCs on the leukocyte function are summarized in table 3 . For the oxidative burst activ-

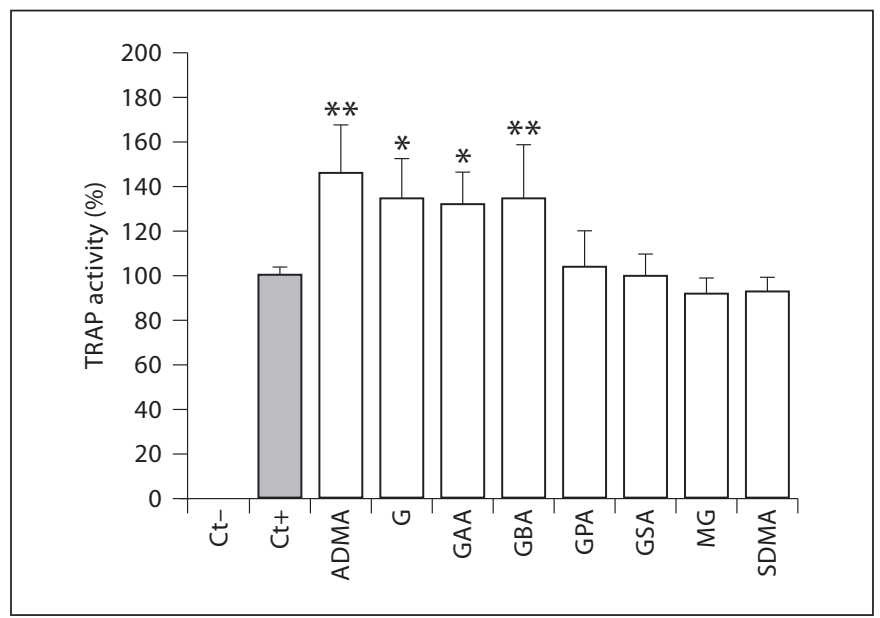

Fig. 5. Effect of GCs on TRAP activity in RAW264.7 cells cultured for 5 days in the presence of RANKL $(30 \mathrm{ng} / \mathrm{ml}, \mathrm{Ct}+)$ and GCs. Results are expressed as mean of $\%$ vs. Ct+ \pm SEM of two independent experiments. ${ }^{*} \mathrm{p}<0.05,{ }^{* *} \mathrm{p}<0.01$ vs. $\mathrm{Ct}+; \mathrm{n}=16$.

ity, most important effects are observed in both monocytes and granulocytes at baseline and especially after stimulation with fMLP, which can be considered representative for the baseline inflammatory status of the uremic patient $[36,37]$. An increased fMLP-stimulated burst in both leukocyte subtypes is observed after incubation with GBA and SDMA. The pathways involved in the proinflammatory effect of SDMA have recently been unraveled in monocytes; SDMA, previously considered inert, enhances the fMLP-stimulated oxidative burst via enhancement of store-operated calcium entry [21]. The stimulation of ROS production in leukocytes is related to oxidative stress, which is present from the early stages of CKD on and is generally considered as one of the key factors causing vascular damage [38]. In contrast to the monocytes and granulocytes, lymphocytes showed no significant changes in their oxidative burst activity after incubation with the GCs.

Although for most GCs an effect on leukocyte oxidative burst activity was observed, only ADMA, GPA and CT directly affected the activity of the NADPH oxidase, the main enzyme involved in ROS production. Other enzymes involved in ROS production, like superoxide dismutase and myeloperoxidase, or a component in the pathway upstream of the enzyme might also be affected by the GCs, but this needs further research.

Several monocyte and granulocyte surface receptors are related to inflammation. The $\beta_{2}$-integrins play a key role in the recruitment of leukocytes to sites of inflam- 
Table 3. Overview of the effect of the GCs on monocyte, granulocyte and lymphocyte function

\begin{tabular}{|c|c|c|c|c|c|c|c|c|c|c|}
\hline & ADMA & CT & $\mathrm{CTN}$ & G & GAA & GBA & GPA & GSA & MG & SDMA \\
\hline \multicolumn{11}{|l|}{ Monocytes } \\
\hline \multicolumn{11}{|l|}{ Oxidative burst } \\
\hline Baseline & $\uparrow$ & - & - & $\uparrow$ & - & - & - & - & - & - \\
\hline fMLP & - & - & - & - & - & $\uparrow$ & $\uparrow$ & - & $\uparrow$ & $\uparrow$ \\
\hline E. coli & - & - & - & - & - & - & - & - & - & - \\
\hline PMA & - & - & - & - & - & - & - & $\uparrow$ & - & - \\
\hline \multicolumn{11}{|l|}{ CD expression } \\
\hline CD11a & - & $\uparrow$ & - & - & - & - & - & $\uparrow$ & - & $\uparrow$ \\
\hline CD11b & - & $\uparrow$ & - & - & - & - & - & - & - & $\uparrow$ \\
\hline CD11c & - & $\uparrow$ & - & - & - & $\uparrow$ & - & - & - & - \\
\hline CD14 & $\uparrow$ & $\uparrow$ & $\uparrow$ & - & $\uparrow$ & $\uparrow$ & $\uparrow$ & $\uparrow$ & $\uparrow$ & $\uparrow$ \\
\hline CD18 & - & $\uparrow$ & - & - & - & - & $\uparrow$ & $\uparrow$ & - & - \\
\hline \multicolumn{11}{|l|}{ Granulocytes } \\
\hline \multicolumn{11}{|l|}{ Oxidative burst } \\
\hline Baseline & - & - & - & - & $\uparrow$ & $\uparrow$ & - & - & - & $\uparrow$ \\
\hline fMLP & - & - & - & $\uparrow$ & $\uparrow$ & $\uparrow$ & - & - & - & $\uparrow$ \\
\hline E. coli & - & - & - & - & - & - & $\downarrow$ & - & $\downarrow$ & - \\
\hline PMA & - & - & - & - & - & - & - & - & - & - \\
\hline \multicolumn{11}{|l|}{ CD expression } \\
\hline CD11a & - & - & - & - & - & - & - & - & - & - \\
\hline CD11b & - & - & - & - & - & - & - & - & - & - \\
\hline CD11c & $\uparrow$ & $\uparrow$ & - & - & - & $\uparrow$ & - & - & - & - \\
\hline CD18 & - & $\uparrow$ & $\uparrow$ & $\uparrow$ & - & $\uparrow$ & $\uparrow$ & $\uparrow$ & - & $\uparrow$ \\
\hline CD62 & $\downarrow$ & - & - & - & - & - & - & $\uparrow$ & $\downarrow$ & $\downarrow$ \\
\hline \multicolumn{11}{|l|}{ Lymphocytes } \\
\hline \multicolumn{11}{|l|}{ Oxidative burst } \\
\hline Baseline & - & - & - & - & - & - & - & - & - & - \\
\hline fMLP & - & - & - & - & - & - & - & - & - & - \\
\hline E. coli & - & - & - & - & - & - & - & - & - & - \\
\hline PMA & - & - & - & - & - & - & - & - & - & - \\
\hline NADPH oxidase & $\uparrow$ & $\downarrow$ & - & - & - & - & $\uparrow$ & - & - & - \\
\hline
\end{tabular}

mation and were shown here to be upregulated by several GCs. Caimi et al. [39] found an altered behavior of granulocyte integrin pattern in mild CKD, reflecting a state of granulocyte activation potentially related to the high incidence of cardiovascular events. Fardon et al. [40] suggest that granulocyte accumulation induced by CD11b/CD18 expression contributes to vascular damage in essential hypertension. Decreased expression of CD62L (L-selectin) on granulocytes points to its shedding, a marker of cell activation and a prerequisite for cell migration after attachment of granulocytes to the endothelial cells [41-44]. In patients with CKD, a high CD11b and a low CD62L on the leukocyte surface was previously described by Dou et al. [45]. CD14 expression is enhanced after incubation with nearly all GCs tested and adds to the pro-inflammatory effect of these compounds in monocytes. The present data demonstrate that especially CT and SDMA exert a pro-inflammatory increase in the expression of surface molecules and thus are likely involved in the interaction of leukocytes with endothelial cells, a key step in the process of atherogenesis.

Several dose-response experiments (effects on leukocytic ROS production at baseline and after fMLP stimulation and on NADPH oxidase activity) were performed. Nevertheless, none of them revealed an effect at lower concentrations than the one reported in the present paper.

The effects of the GCs on endothelial cells were also evaluated (table 4). In HUVEC, G, GSA and SDMA decreased endothelial cell proliferation; therefore, these compounds may reduce endothelial repair in response to injury. Similar effects were found previously for the ure- 
Table 4. Overview of effects of the GCs on endothelials cells, smooth muscle cells and OCLs

\begin{tabular}{|c|c|c|c|c|c|c|c|c|c|c|}
\hline & ADMA & CT & CTN & G & GAA & GBA & GPA & GSA & MG & SDMA \\
\hline \multicolumn{11}{|l|}{$\begin{array}{l}\text { Endothelial cells } \\
\text { HUVEC }\end{array}$} \\
\hline $\begin{array}{l}\text { BrdU } \\
\text { Incorporation } \\
\text { HAEC }\end{array}$ & - & - & - & $\downarrow$ & - & - & - & $\downarrow$ & - & $\downarrow$ \\
\hline Cytolysis & - & - & - & - & - & - & - & - & - & - \\
\hline ATP content & - & - & - & - & - & - & - & - & - & - \\
\hline \multicolumn{11}{|l|}{$\begin{array}{l}\text { Smooth muscle cells } \\
\text { AoSMC }\end{array}$} \\
\hline Cytolysis & - & - & - & - & - & - & - & - & - & - \\
\hline $\begin{array}{l}\text { ATP content } \\
\text { HVSMC }\end{array}$ & - & - & - & - & - & - & - & - & - & - \\
\hline Proliferation & - & NA & NA & - & - & - & - & - & - & - \\
\hline Calcification & $\downarrow$ & NA & NA & - & - & - & - & $\downarrow$ & - & $\downarrow$ \\
\hline \multicolumn{11}{|l|}{ OCLs } \\
\hline Proliferation & - & NA & NA & - & - & - & - & - & - & - \\
\hline Osteoclastogenesis & $\uparrow$ & NA & NA & $\uparrow$ & $\uparrow$ & $\uparrow$ & - & - & - & - \\
\hline
\end{tabular}

mic toxins $p$-cresol and indoxyl sulfate, resulting in a decrease in endothelial wound repair [32].

Considering the effects of GCs on osteoblast and osteoclast-like cells (table 4), from the vascular point of view the results seem contradictory to those described above (pro-inflammatory) on leukocytes and endothelial cells. Inhibition of the Pi-induced calcification observed in the presence of ADMA, GSA and SDMA in the HVSMC and induction of osteoclast differentiation in RAW264.7 cell line in the presence of ADMA, G, GAA and GPA might be rather vasoprotective. Nevertheless, from the bone perspective, these GCs could contribute to bone disease observed in CKD patients. A stimulation of osteoclastogenesis was demonstrated previously by Menaa et al. [46] for $\beta_{2}$-microglobulin, supporting its involvement in bone resorption. The breakdown of the bone may result in a transfer of calcium from the bone to the blood, which may lead to vascular calcification.

In general, the data presented here suggest that the GCs, although structurally related, show a different in vitro behavior. Mainly pro-inflammatory/pro-atherogenic effects were observed, especially on leukocytes. The compound exerting the highest number of pro-inflammatory effects is SDMA, which further strengthens the observations by Bode-Böger et al. [20] and Schepers et al. [21] that this compound is not biologically inert. A limi- tation of the present study includes that incubation periods are limited from only $10 \mathrm{~min}$ to a maximum of 7 days. Since CKD is a disease that may last for years, some potential toxic effects of the GCs due to chronic exposure might not be unraveled by this in vitro approach.

Finally, although the GCs are small and water-soluble, like urea, and therefore believed to be easily removed by modern dialysis strategies, recent data suggest that they have a different kinetic behavior compared to urea. Eloot et al. $[47,48]$ demonstrated that the GCs were characterized by a markedly larger distribution volume as compared to urea so that they can be classified as difficult to remove uremic retention solutes, like middle molecules and protein-bound compounds. Recently, a mathematical two-compartmental kinetic model demonstrated that prolonged dialysis in combination with an increased dialysis frequency are effective in significantly reducing concentration of the GCs compared to classical hemodialysis (three times $4 \mathrm{~h}$ per week) [49].

The present paper evaluated, for the first time, the toxicity of ten members of a group of uremic solutes in parallel in different in vitro models relevant for evaluating their cardiovascular damaging potential according to a standardized protocol. By expanding this approach to other known uremic retention solutes, the in vitro data will lead to the identification of the potential culprits of 
the uremic syndrome. This gathering of experimental data obtained in a standardized way will allow the classification of uremic toxins according to their toxicity, indicating the most important substances to be submitted to more in-depth pathophysiological research finally leading to the development of new pharmacologic and more specific removal techniques. In this way, the present study can be considered as a pilot analysis guiding future multifaceted uremic toxin research.

\section{Acknowledgements}

The European Uremic Toxin Work Group (EUTox) has been created within the European Society for Artificial Organs (ESAO) to discuss and analyze matters related to the identification, characterization, analytic determination, and evaluation of biological activity of uremic retention solutes. More information about the EUTox, which is responsible for this publication, can be obtained at the website: http://uremic-toxins.org.

\section{Disclosure Statement}

\section{References}

$\checkmark 1$ Van Biesen W, De Bacquer D, Verbeke F, Delanghe J, Lameire N, Vanholder R: The glomerular filtration rate in an apparently healthy population and its relation with cardiovascular mortality during 10 years. Eur Heart J 2007;28:478-483.

2 Vanholder R, Massy Z, Argiles A, Spasovsk G, Verbeke F, Lameire N: Chronic kidney disease as cause of cardiovascular morbidity and mortality. Nephrol Dial Transplant 2005;20:1048-1056.

-3 Dhingra H, Laski ME: Outcomes research in dialysis. Semin Nephrol 2003;23:295-305.

4 Coresh J, Selvin E, Stevens LA, Manzi J, Kusek JW, Eggers P, Van Lente F, Levey AS: Prevalence of chronic kidney disease in the United States. JAMA 2007;298:2038-2047.

5 Stenvinkel P, Carrero JJ, Axelsson J, Lindholm B, Heimburger O, Massy Z: Emerging biomarkers for evaluating cardiovascular risk in the chronic kidney disease patient: how do new pieces fit into the uremic puzzle? Clin J Am Soc Nephrol 2008;3:505-521.

-6 Stenvinkel P, Heimburger O, Lindholm B, Kaysen GA, Bergstrom J: Are there two types of malnutrition in chronic renal failure? Evidence for relationships between malnutrition, inflammation and atherosclerosis (MIA syndrome). Nephrol Dial Transplant 2000;15:953-960

7 Vanholder R, Argiles A, Baurmeister U, Brunet P, Clark W, Cohen G, De Deyn PP, Deppisch R, Descamps-Latscha B, Henle T, Jorres A, Massy ZA, Rodriguez M, Stegmayr B, Stenvinkel P, Wratten ML: Uremic toxicity: present state of the art. Int J Artif Organs 2001;24:695-725.

-8 London GM, Marchais SJ, Guerin AP, Metivier F: Arteriosclerosis, vascular calcifications and cardiovascular disease in uremia. Curr Opin Nephrol Hypertens 2005; 14:525531.

-9 Ross R: Atherosclerosis - an inflammatory disease. N Engl J Med 1999;340:115-126.
10 De Deyn PP, Marescau B, Cuykens JJ, Van Gorp L, Lowenthal A, De Potter WP: Guanidino compounds in serum and cerebrospinal fluid of non-dialyzed patients with renal insufficiency. Clin Chim Acta 1987;167:8188.

11 De Deyn PP, Marescau B, D’Hooge R, Possemiers I, Nagler J, Mahler C: Guanidino compound levels in brain regions of non-dialyzed uremic patients. Neurochem Int 1995; 27:227-237.

12 De Deyn PP, D’Hooge R, Van Bogaert PP, Marescau B: Endogenous guanidino compounds as uremic neurotoxins. Kidney Int Suppl 2001;78:S77-S83.

13 Glorieux GL, Dhondt AW, Jacobs P, Van Langeraert J, Lameire NH, De Deyn PP, Vanholder RC: In vitro study of the potential role of guanidines in leukocyte functions related to atherogenesis and infection. Kidney Int 2004;65:2184-2192.

14 Perna AF, Ingrosso D, Satta E, Lombardi C, Galletti P, D'Aniello A, De Santo NG: Plasma protein aspartyl damage is increased in hemodialysis patients: studies on causes and consequences. J Am Soc Nephrol 2004; 15 : 2747-2754.

15 Cooke JP: Asymmetrical dimethylarginine: the Uber marker? Circulation 2004; 109 : 1813-1818.

16 Kielstein JT, Tsikas D, Fliser D: Effects of asymmetric dimethylarginine infusion in humans. Eur J Clin Pharmacol 2005;62:3944.

17 Meinitzer A, Seelhorst U, Wellnitz B, Halwachs-Baumann G, Boehm BO, Winkelmann BR, Marz W: Asymmetrical dimethylarginine independently predicts total and cardiovascular mortality in individuals with angiographic coronary artery disease (the Ludwigshafen Risk and Cardiovascular Health study). Clin Chem 2007;53:273-283.

18 Vallance P, Leone A, Calver A, Collier J, Moncada S: Accumulation of an endogenous inhibitor of nitric oxide synthesis in chronic renal failure. Lancet 1992;339:572-575.
19 Zoccali C, Bode-Böger S, Mallamaci F, Benedetto F, Tripepi G, Malatino L, Cataliotti A, Bellanuova I, Fermo I, Frolich J, Böger R: Plasma concentration of asymmetrical dimethylarginine and mortality in patients with end-stage renal disease: a prospective study. Lancet 2001;358:2113-2117.

20 Bode-Böger SM, Scalera F, Kielstein JT, Martens-Lobenhoffer J, Breithardt G, Fobker M, Reinecke H: Symmetrical dimethylarginine: a new combined parameter for renal function and extent of coronary artery disease. J Am Soc Nephrol 2006;17:1128-1134.

21 Schepers E, Glorieux G, Dhondt A, Leybaert L, Vanholder R: Role of symmetric dimethylarginine in vascular damage by increasing ROS via store-operated calcium influx in monocytes. Nephrol Dial Transplant 2008; 25:1429-1435.

22 Cohen G, Glorieux G, Thornalley P, Schepers E, Meert N, Jankowski J, Jankowski V, Argiles A, Adeerstam B, Brunet P, Cerinin C, Dou L, Deppisch R, Marescau B, Massy Z, Perna A, Raupachova J, Rodriguez M, Stegmayr B, Vanhyolder R, Horl WH: Review on uraemic toxins III: recommendations for handling uraemic retention solutes in vitro towards a standardized approach for research on uraemia. Nephrol Dial Transplant 2007;22:3381-3390.

23 De Deyn P, Marescau B, Lornoy W, Becaus I, Lowenthal A: Guanidino compounds in uraemic dialysed patients. Clin Chim Acta 1986;157:143-150.

24 Kang ES, Tevlin MT, Wang YB, Chiang TM, Cardenas R, Myers LK, Acchiardo SR: Hemodialysis hypotension: interaction of inhibitors, iNOS, and the interdialytic period. Am J Med Sci 1999;317:9-21.

25 Marescau B, Nagels G, Possemiers I, De Broe ME, Becaus I, Billiouw JM, Lornoy W, De Deyn PP: Guanidino compounds in serum and urine of nondialyzed patients with chronic renal insufficiency. Metabolism 1997;46:1024-1031. 
-26 Tanaka A, Takahashi Y, Mizokuchi M, Shimada N, Koide $\mathrm{H}$ : Plasma, urinary, and erythrocyte concentrations of guanidino compounds in patients with chronic renal failure. Ren Fail 1999;21:499-514.

-27 Vanholder R, De Smet R, Glorieux G, Argiles A, Baurmeister U, Brunet P, Clark W, Cohen G, De Deyn PP, Deppisch R, Descamps-Latscha B, Henle T, Jorres A, Lemke HD, Massy A, Passlick-Deetjen J, Rodriguez M, Stegmayr B, Stenvinkel P, Tetta C, Wanner C, Zidek W: Review on uremic toxins: classification, concentration, and interindividual variability. Kidney Int 2003;63:1934-1943.

$\checkmark 28$ Wengle B, Hellstrom K: Volatile phenols in serum of uraemic patients. Clin Sci 1972;43: 493-498.

-29 Schepers E, Meert N, Glorieux G, Goeman J, Van der Eycken J, Vanholder R: p-Cresylsulphate, the main in vivo metabolite of $p$-cresol, activates leucocyte free radical production. Nephrol Dial Transplant 2007;22: 592-596.

-30 Tepel M, Echelmeyer M, Orie NN, Zidek W: Increased intracellular reactive oxygen species in patients with end-stage renal failure: effect of hemodialysis. Kidney Int 2000;58: 867-872.

-31 Jaffe EA, Nachman RL, Becker CG, Minick CR. Culture of human endothelial cells derived from umbilical veins. Identification by morphologic and immunologic criteria. J Clin Invest 1973;52:2745-2756.

-32 Dou L, Bertrand E, Cerini C, Faure V, Sampol J, Vanholder R, Berland Y, Brunet P: The uremic solutes $p$-cresol and indoxyl sulfate inhibit endothelial proliferation and wound repair. Kidney Int 2004;65:442-451.

>33 Jono S, McKee MD, Murry CE, Shioi A, Nishizawa Y, Mori K, Morii H, Giachelli CM: Phosphate regulation of vascular smooth muscle cell calcification. Circ Res 2000; 87:E10-E17.
34 Mozar A, Haren N, Chasseraud M, Louvet L, Maziere C, Wattel A, Mentaverri R, Morliere P, Kamel S, Brazier M, Maziere JC, Massy ZA: High extracellular inorganic phosphate concentration inhibits RANK-RANKL signaling in osteoclast-like cells. J Cell Physio 2008;215:47-54

35 Vanholder R, Abou-Deif O, Argiles A, Baurmeister U, Beige J, Brouckaert P, Brunet $\mathrm{P}$, Cohen G, De Deyn PP, Drueke TB, Fliser D, Glorieux G, Herget-Rosenthal S, Horl WH, Jankowski J, Jorees A, Massy ZA, Mischak H, Perna A, Rodriguez-Poritllo JM, Spasovski G, Stegmayr BG, Stenvinkel P, Thornalley PJ, Wanner C, Wiecek A: The role of EUTox in uremic toxin research. Semin Dial 2009;22: 323-328.

36 Kemmerich B, Pennington JE: Different calcium and oxidative metabolic responses in human blood monocytes during exposure to various agonists. J Leukoc Biol 1988;43:125132.

37 Stenvinkel P, Alvestrand A: Inflammation in end-stage renal disease: sources, consequences, and therapy. Semin Dial 2002;15 329-337.

38 Zalba G, Fortuno A, Diez J: Oxidative stress and atherosclerosis in early chronic kidney disease. Nephrol Dial Transplant 2006;21: 2686-2690.

39 Caimi G, Montana M, Carollo C, Porretto F, Vaccaro F, Canino B, Lo PR: Polymorphonuclear leukocyte integrins in chronic renal failure. Clin Hemorheol Microcirc 2005;32: 43-49

40 Fardon NJ, Wilkinson R, Thomas TH: Rapid fusion of granules with neutrophil cell membranes in hypertensive patients may increase vascular damage. Am J Hypertens 2001;14 927-933.

41 Ebisawa M, Bochner BS, Georas SN, Schleimer RP: Eosinophil transendothelial migration induced by cytokines. I. Role of endothelial and eosinophil adhesion molecules in IL-1 $\beta$-induced transendothelial migration. J Immunol 1992;149:4021-4028.
42 Walker C, Rihs S, Braun RK, Betz S, Bruijnzeel PL: Increased expression of CD11b and functional changes in eosinophils after migration across endothelial cell monolayers. J Immunol 1993;150:4061-4071.

43 Kansas GS: Selectins and their ligands: current concepts and controversies. Blood 1996; 88:3259-3287.

44 Schleiffenbaum B, Spertini O, Tedder TF: Soluble L-selectin is present in human plasma at high levels and retains functional activity. J Cell Biol 1992;119:229-238.

45 Dou L, Brunet P, Dignat-George F, Sampol J, Berland Y: Effect of uremia and hemodialysis on soluble L-selectin and leukocyte surface CD11b and L-selectin. Am J Kidney Dis 1998;31:67-73.

46 Menaa C, Esser E, Sprague SM: Beta-2-microglobulin stimulates osteoclast formation. Kidney Int 2008;73:1275-1281.

$\checkmark 47$ Eloot S, Torremans A, De Smet R, Marescau B, De Wachter D, De Deyn PP, Lameire N, Verdonck P, Vanholder R: Kinetic behavior of urea is different from that of other watersoluble compounds: the case of the guanidino compounds. Kidney Int 2005;67:15661575.

48 Eloot S, Torremans A, De Smet R, Marescau B, De Deyn PP, Verdonck P, Vanholder R: Complex compartmental behavior of small water-soluble uremic retention solutes: evaluation by direct measurements in plasma and erythrocytes. Am J Kidney Dis 2007;50: 279-288.

$\checkmark 4$ Eloot S, Van Biesen W, Dhondt A, De Smet R, Marescau B, De Deyn PP, Verdonck P, Vanholder R: Impact of increasing haemodialysis frequency versus haemodialysis duration on removal of urea and guanidino compounds: a kinetic analysis. Nephrol Dial Transplant 2009;24:2225-2232. 